\title{
Disparities, variations, inequalities or inequities: whatever you call them, we need data to monitor them
}

Jennifer S. Mindell(1)

\begin{abstract}
Health inequalities are a problem in high, middle and low income countries. Most are unfair ('inequities') and could be minimised but primarily through policies outside the health service.

In the US, the Center for Diseases Control has used high quality, nationally-available data to monitor conditions and determinants of health among different groups (by sex, disability, race, ethnicity, and language) to motivate action to reduce inequalities. In the UK, the 10 top level 'health' indicators in London at the turn of the millennium included unemployment, education, housing quality, crime, air pollution, road travel injuries, as well as traditional health measures. Most of these affect mental and physical health through social determinants or adverse environmental exposures. Current inequalities monitoring in England includes a Local Basket of Inequalities Indicators focusing on a wide range of determinants of health as well as traditional health metrics.

Israel, like the US, has above average socio-economic inequalities but has universal healthcare. Health inequalities in Israel occur within different Jewish groups and by income, education, ethnicity, and religion, with disadvantages often clustering. Current monitoring in Israel focuses on health outcomes and 'midstream' healthcare-related provision. I agree with Abu-Saad and her colleagues that including monitoring of social determinants of health is crucial to identify and tackle health inequalities in Israel.

National, 'upstream', interventions are the most effective ways to reduce inequalities and improve the population's health. High-level political support is crucial for this. While a 'Health in all Policies' approach combined with political will to 'leave no one behind' can lead to great improvements, regular monitoring is essential, to: identify the inequities; plan appropriate and effective, targeted interventions; implement and evaluate them; and change them where needed. All of this requires adequate and timely data on health and its determinants, including information about undiagnosed and poorly controlled disease, obtained from the general population not just those attending for healthcare, analysed for each population sub-group at risk of experiencing inequalities.

This is a commentary on https://doi.org/10.1186/s13584-018-0208-1
\end{abstract}

Keywords: Disparities, Variations, Inequalities, Inequities, Sustainable development goals (SDGs)

\section{Main text}

Disparities, inequalities, and inequities

On reading the paper by Abu-Saad, Avni and Kalter-Leibovici [1], my initial reaction to the title and abstract was one of dismay that the term 'health disparities' is being used in Israel, as it is in the USA [2]. The term reminds me of the Thatcher years in England, when 'health variations' was the term the government considered acceptable, disregarding considerations of

Correspondence: j.mindell@ucl.ac.uk

UCL, Gower Street, London WC1E 6BT, UK social justice; those working for the government were banned from talking about 'social inequalities' [3, 4].

I believe that "inequality" is a more appropriate term than "disparity." For example, during the Thatcher period in England, home ownership increased markedly. However, figures from the Institute for Fiscal Studies show that over the 11 years from 1979 to 1990 , the mean income, adjusted for inflation, rose by $4.6 \%$ among the poorest decile of households but by $46.9 \%$ among the richest decile: the income in the latter group went from 3.1 times to 4.4 times that of the former, leading to a

(c) The Author(s). 2019 Open Access This article is distributed under the terms of the Creative Commons Attribution 4.0 International License (http://creativecommons.org/licenses/by/4.0/), which permits unrestricted use, distribution, and 
dramatic increase in socioeconomic inequalities during that time. The number of children living in poverty also increased from 1.7 million to 3.3 million [5]. All these inequalities have continued to increase since then [5].

According to the U.S. Centers for Disease Control and Prevention (CDC): "Health equity is when everyone has the opportunity to be as healthy as possible" and "Health disparities are differences in health outcomes and their causes among groups of people" [6]. In most countries worldwide, at least in public health circles, 'inequalities' refer to differences and 'inequities' to unfair differences, such as in a recent report from Canada [7].

Fortunately, once I reached the paper itself, my concern was allayed, as the main text opens with the statement that "Health disparities or inequities are defined as avoidable and unjust differences in exposure and vulnerability to health risk factors, health-care outcomes, and the social and economic consequences of these outcomes", citing the World Health Organization [8].

\section{Health inequities in Israel and the U.S.}

The paper by Abu-Saad and colleagues focuses on the U.S., noting its lack of national healthcare insurance and its high poverty and income inequality relative to most OECD countries, and draws lessons on monitoring the effectiveness of attempts to reduce these inequities. Israel resembles the U.S. regarding the above average extent of inequalities and resembles the UK (which also has inequalities by age, gender, income, and ethnicity $[9$, 10]) in having universal healthcare. Abu-Saad et al. provide evidence of the health inequities in Israel within the different Jewish groups as well as between the broader majority and minority populations, mentioning the collinearity in many cases between income, education, ethnicity, and religion. Indeed, Daoud et al. showed that after adjusting for socio-economic differences in education and income, Arabs in Israel had better self-reported health than longstanding Jewish residents [11].

The paper then describes the impressive series of ten-yearly Healthy People goals in the U.S., with the changing priorities each decade. However, having so many priorities can result in no priorities in practice. Therefore, 'Leading health indicators' were identified by $\mathrm{CDC}$, using data that were high quality; available nationally; monitored conditions or determinants of health that were of public health importance or where effective, feasible interventions exist for a health condition suffered inequitably by different groups; and where the indicators could motivate action.

While Israeli efforts to reduce health inequities began about a decade ago, those in the U.S. started in the 1980s. However, it was not until 2011 that the U.S. authorities set consistent definitions and minimum data standards for the long list of parameters associated with health inequalities, including sex, disability, race, ethnicity, and language.

\section{'Upstream' and 'downstream' policies}

Hosseinpoor et al. noted that while the Millennium Development Goals focused on reduced inequalities between countries, the Sustainable Development Goals (SDGs) aim to reduce inequalities within countries [12]. It is ironic that both the Millennium and Sustainable Development Goals were intended primarily for low and middle income countries, yet some of the worst inequities occur in the U.S. [13]. The problem is, of course, that most health inequities are related primarily to social determinants of health [14], requiring political will to address these.

While Abu-Saad and colleagues report on high-level political support in the U.S. from the mid-1980s and subsequently [1], ongoing support seems unlikely in the current political climates in the U.S., Israel, and the UK, except within the limits of continuing legal requirements. This is particularly pertinent given the findings by many non-governmental organisations, reported by Abu-Saad et al., that early initiatives tended to focus on individual behaviours and healthcare [1], both known to be the least effective ways of reducing inequalities compared with national, 'upstream', interventions.

For example, Gillespie et al. compared two approaches to reducing salt intake in the population in the UK, where about $80-85 \%$ of sodium intake comes from manufactured food. They estimated that mandatory reformulation of manufactured food would have ten times more impact than social marketing to influence individual behaviour would. More importantly, in the context of inequalities, mandatory reformulation would have a $49 \%$ greater effect in the most deprived compared with the most affluent [15] whereas social marketing would not reduce health inequalities (and could actually increase them).

\section{Social determinants of health}

In most countries, there are no inequalities in polio because polio has been eradicated. That is also the desired endpoint for smoking and other health-harming behaviours; universal adoption of activities benefitting health, including preventive care, early diagnosis, and effective management would eradicate healthcare-driven inequalities. However, as mentioned above, most health inequalities are driven by inequalities in the determinants of health.

The 'health' indicators used in London almost two decades ago took a different approach to monitoring health and inequalities in London than either the US approach or what Abu-Saad et al. suggest. The 10 top level 'health' indicators in London were: unemployment overall and 
among black and minority ethnic people; educational attainment; the proportion of homes judged unfit to live in; the domestic burglary rate; air quality indicators $\left(\mathrm{NO}_{2}\right.$ and $\left.\mathrm{PM}_{10}\right)$; road traffic injury rate; life expectancy at birth; infant mortality rate; and the proportion of people with self-assessed good health [16]. Most of these are factors that affect mental and physical health through social determinants (education, unemployment, housing, security) or adverse environmental exposures (air pollution) rather than direct measures of poor - or good - health.

In the past decade there have been changes in approach by Healthy People 2020 and CDC to include monitoring inequalities in social determinants of health. Abu-Saad et al. report the critique of such indicators, which compartmentalise socio-economic inequity rather than considering the clustering and co-existence of many aspects of disadvantage within certain groups. They recommend that Israel should include social determinants of health as outcomes/indicators of inequality in addition to outcome measures more immediately recognisable as 'health' indicators [1]. I would encourage an approach that follows the example of London from the turn of the millennium, as it can focus political minds on health and its social determinants, not just on healthcare.

Current monitoring of national, regional and local level inequalities in England include the Compendium of Indicators produced by NHS Digital [17] and Public Health England (PHE)'s Outcomes Frameworks [18]. The former includes data on cancer, public health, area deprivation, and the Local Basket of Inequalities Indicators, which includes unemployment, poverty, housing, homelessness, education, crime, pollution, community development, lifestyle behavioural risk factors for chronic non-communicable diseases (NCDs), access to healthcare, injuries, mental health, maternal and child health, older people, and tackling NCDs [19]. PHE's Outcomes Framework, published quarterly, aims to support public health efforts to improve the public's health, "and to improve the health of the poorest fastest" [18]. However, the problem remains that the determinants of inequalities lie primarily within the remit of national government, although local government policies can improve or exacerbate such inequalities.

\section{Health examination surveys}

One aspect missing from Abu-Saad, Avni and Kalter-Leibovici's account of monitoring health inequalities and their list of indicators used in the U.S. is the consideration of undiagnosed disease. This cannot be detected using healthcare data, nor from health interview surveys, but requires biophysical measurements of a random sample of the general population [20]. Such surveys are now routine in many countries across Europe [21] and other high and middle income countries (e.g. across Latin America [22]) and also in low income countries (e.g. in sub-Saharan Africa [23, 24]). A health examination survey (HES) costs more to run than a health interview survey but the information is more valuable, with documented examples of use in national policy-making $[25,26]$. Inequalities exist in the prevalence of NCDs $[9,27,28]$, related to inequalities in risk factors and in socio-economic and other circumstances [29], and in obtaining a diagnosis in the presence of disease $[27,30]$, related at least in part to the availability of healthcare insurance [30], but demographic and socio-economic inequalities in late diagnosis occur even in high income countries with universal healthcare, such as Israel and the UK [31].

Like many countries, Israel had a health interview survey (in 2004) and more recently as part of the European Health Interview survey (EHIS) but had no health examination survey undertaken. This has changed, to a limited extent, by the development of MABAT, the National Health and Nutrition survey, based on a random sample of the general population. As with the Health Survey for England, different surveys have had a different focus. MABAT zahav, 2005-06, was limited to people aged 65+ who were members of either of the two largest HMOs in Israel, covering $87 \%$ of the Israeli population of that age. Handgrip was also measured in these participants, as it was in people aged $65+$ participating in the HSE 2005.

MABAT includes anthropometric measurements to obtain an accurate assessment of obesity prevalence [32]. Blood pressure was also measured so the prevalence of undiagnosed hypertension can be estimated, using measurements in conjunction with information from asking about (self-reported) doctor-diagnosed high blood pressure. This is thus comparable with the approaches taken in most health examination surveys but a more limited range of undiagnosed diseases can be detected in MABAT compared with the UK and USA. Information on undiagnosed disease (including, for example, a measure of blood glucose or serum creatinine for diabetes or kidney disease) would also help to target interventions to reduce health inequalities due to unequal use of healthcare, as there is more to access and equitable use of healthcare than it being freely available [33], even after adjustment for the increased need in poorer people $[34,35]$.

\section{Conclusions}

Health inequalities are a problem in high, middle and low income countries. Most are unfair ('inequities') and could be minimised but primarily through policies outside the health service. While a 'Health in all Policies' 
approach combined with political will to 'leave no one behind' can lead to great improvements, regular monitoring is essential to: identify the inequities; plan appropriate and effective interventions; implement and target them; evaluate them; and change them where needed. All of this requires adequate and timely data, obtained from the general population using health examination surveys in addition to healthcare data, to ensure undiagnosed disease in included.

\section{Abbreviations}

CDC: U.S. Centers for Disease Control and Prevention; NCDs: Chronic noncommunicable diseases; NHS: National Health Service; PHE: Public Health England; SDGs: Sustainable Development Goals

\section{Acknowledgements}

I thank the staff commissioning MABAT for information about the surveys.

\section{Funding}

No funding was received for writing this commentary.

\section{Availability of data and materials}

Not applicable.

\section{Authors' contributions}

JM was invited by the editor to write this commentary. JM is the sole author, thus planned, drafted and revised the manuscript herself.

\begin{abstract}
Authors' information
JM is Professor of Public Health at UCL, London, UK, where she leads the UCL team dealing with the Health Survey for England. A public health physician, she works with colleagues across Europe and Latin America, comparing methods and data from health examination studies. She also works in the field of transport and health.
\end{abstract}

\section{Ethics approval and consent to participate}

Not applicable.

\section{Consent for publication}

Not applicable.

\section{Competing interests}

The author declares that she has no competing interests.

\section{Publisher's Note}

Springer Nature remains neutral with regard to jurisdictional claims in published maps and institutional affiliations.

Received: 24 March 2019 Accepted: 5 April 2019

Published online: 29 April 2019

\section{References}

1. Abu-Saad K, Avni S, Kalter-Leibovici O. Health disparities monitoring in the U.S.: lessons for monitoring efforts in Israel and other countries. Isr J Health Pol Res. 2018:7:14

2. National Academies of Sciences, Engineering, and Medicine; Health and Medicine Division; Board on Population Health and Public Health Practice; Committee on Community-Based Solutions to Promote Health Equity in the United States, Baciu A, Negussie Y, Geller A, et al. Communities in Action: Pathways to Health Equity. In: The State of Health Disparities in the United States. Washington (DC): National Academies Press (US); 2017. https://www. ncbi.nlm.nih.gov/books/NBK425844/ Accessed 21 Dec 2018.

3. Maryon Davis A. Thatcher's health legacy. Environmental Health News. 2013 www.ehn-online.com/news8792.html Accessed 21 Dec 2018

4. Scott-Samuel A, Bambra C, Hunter DJ, McCartney G, Smith K. The impact of Thatcherism on health and well-being in Britain. Int J Health Services. 2014; 44:53-71.
5. Ball J. The Thatcher effect: what changed and what stayed the same. The Guardian newspaper. 2013. https://www.theguardian.com/politics/2013/apr/ 12/thatcher-britain Accessed 31 Dec 2018

6. Centers for Disease Control and Prevention. Strategies for Reducing Health Disparities. In: Selected CDC-Sponsored Interventions, United States; 2016. https://www.cdc.gov/minorityhealth/strategies2016/index.html Accessed 31 Dec 2018

7. Public Health Agency of Canada. Toward Health Equity: Canadian Approaches to the Health Sector Role. Ottawa: Public Health Agency of Canada; 2014. https://www.who.int/social_determinants/publications/ 9781100235264/en/ Accessed 31 Dec 2018

8. World Health Organization. The Innov8 approach for reviewing national health programmes to leave no one behind. In: Technical handbook. Geneva: WHO; 2016. https://www.who.int/life-course/publications/innov8technical-handbook/en/ Accessed 31 Dec 2018

9. Fuller E, Mindell J (eds). The Health Survey for England 2017. Leeds, UK: NHS Digital, 2018. https://digital.nhs.uk/data-and-information/publications/ statistical/health-survey-for-england/2017 Accessed 31 Dec 2018

10. Mindell JS, Knott CS, Ng Fat LS, Roth MA, Manor O, Soskolne V, Daoud N. Explanatory factors for health inequalities across different ethnic and gender groups: data from a national survey in England. J Epidemiol Community Health. 2014;68:1133-1144. http://dx.doi.org/https://doi.org/10.1136/jech2014-203927

11. Daoud N, Soskolne V, Mindell JS, Roth MA, Manor O. Ethnic inequalities in health between Arabs and Jews in Israel: the relative contribution of individual-level factors and the living environment. Int J Public Health. 2018; 63: 313. https://doi.org/https://doi.org/10.1007/s00038-017-1065-3

12. Hosseinpoor AR, Bergen N, Magar V. Monitoring inequality: an emerging priority for health post-2015. Bull WHO. 2015;93:591-591A. doi: http://dx.doi. org/https://doi.org/10.2471/BLT.15.162081

13. Hero JO, Zaslavsky AM, Bleondon RJ. The United States Leads Other Nations In Differences By Income In Perceptions Of Health And Health Care. Health Affairs. 2017;36, No. 6: Pursuing Health Equity. https://doi.org/https://doi.org/ 10.1377/hlthaff.2017.0006

14. Commission on Social Determinants of Health. Marmot M (Chair). Closing the gap in a generation. In: Health equity through action on the social determinants of health. Geneva: World Health Organization; 2008. https:// www.who.int/social_determinants/thecommission/finalreport/en/ Accessed 31 Dec 2018

15. Gillespie DOS, Allen K, Guzman-Castillo M, Bandosz P, Moreira P, McGill R, Anwar E, Lloyd-Williams F, Bromley H, Diggle PJ, Capewell S, O'Flaherty M. The Health Equity and Effectiveness of Policy Options to Reduce Dietary Salt Intake in England: Policy Forecast. PLoS ONE. 2015;10(7):e0127927. https:// doi.org/10.1371/journal.pone.0127927

16. The London Health Commission. Health in London: Review of the London Health Strategy high level indicators. London: Greater London Authority; 2003.

17. NHS Digital. Compendium of Population Health Indicators. https://digital. nhs.uk/data-and-information/publications/ci-hub/compendium-indicators Accessed 31 Dec 2018

18. Public Health England. Public Health Outcomes Framework. https:// fingertips.phe.org.uk/profile/public-health-outcomes-framework Accessed 31 Dec 2018

19. NHS Digital. Compendium of Population Health Indicators: Local basket of inequality indicators (LBOI). https://digital.nhs.uk/data-and-information/ publications/clinical-indicators/compendium-of-population-healthindicators/compendium-local-basket-of-inequality-indicators-lboi/current Accessed 31 Dec 2018

20. Tolonen H, Koponen P, Mindell JS, Männistö S, Giampaoli S, Dias CM, Tuovinen T, Gößwald A, Kuulasmaa K, for the European Health Examination Survey Pilot Project. Under-estimation of obesity, hypertension and high cholesterol by self-reported data: comparison of self-reported information and objective measures from health examination surveys. Eur JPublic Health. 2014;24:941-8 https://doi.org/10.1093/eurpub/cku074

21. Tolonen H, Koponen P, Mindell J, Männistö S, Kuulasmaa K. Health Examination Survey - towards a sustainable monitoring system, Eur J Public Health. 2014;24:338-344. https://doi.org/https://doi.org/10.1093/eurpub/ ckt107

22. Mindell JS, Moody A, Vecino-Ortiz, Al Alfaro T, Frenz P, Scholes S, Gonzalez SA, Margozzini P de Oliveira C, Sanchez Romero LM, Alvarado A, Cabrer S, Sarmiento OL, Triana CA, Barquera S. Comparison of Health Examination 
Survey Methods in Brazil, Chile, Colombia, Mexico, England, Scotland, and the United States. Am J Epidemiol. 2017;186:648-658. https://doi.org/https:// doi.org/10.1093/aje/kw×045

23. World Health Organization. STEPS: A Framework for Surveillance: The WHO STEPwise Approach to Surveillance of Non-communicable Diseases (STEPS). Geneva: WHO; 2003. https://www.who.int/ncd_surveillance/en/steps_ framework_dec03.pdf Accessed 31 Dec 2018

24. Cham B, Scholes S, Ng Fat L, Badjie O, Mindell JS. Burden of hypertension in The Gambia: evidence from a national World Health Organization (WHO) STEP survey. Int J Epidemiol. 2018;47:860-871. https://doi.org/https://doi. org/10.1093/ije/dyx279

25. Oyebode O, Mindell JS. A review of the use of health examination data from the Health Survey for England in government policy development and implementation. Arch Public Health. 2014;72:24. https://doi.org/https://doi. org/10.1186/2049-3258-72-24

26. Oyebode $\mathrm{O}$, Mindell J. Use of Health Survey for England in policy making. Obes Rev. 2013;14:463-476. https://doi.org/https://doi.org/10.1111/obr.12024

27. Xiaohui $\mathrm{H}$. Urban-rural disparity of overweight, hypertension, undiagnosed hypertension, and untreated hypertension in China. Asia Pac J Public Health. 2008;20(2):159-169. https://doi.org/https://doi.org/10.1177/ 1010539507312306

28. Pearson-Stuttard J, Bajekal M, Scholes S, O'Flaherty M, Hawkins NM, Raine R, Capewell S. Recent UK trends in the unequal burden of coronary heart disease. Heart. 2012;98:1573-1582. http://dx.doi.org/https://doi.org/10.1136/ heartjnl-2012-302435

29. Mackenbach JP, Stirbu I, Roskam AJ, Schaap MM, Menvielle G, Leinsalu M, Kunst $A E$, for the European Union Working Group on Socioeconomic Inequalities in Health. Socioeconomic Inequalities in Health in 22 European Countries. N Engl J Med. 2008;358:2468-81. https://www.nejm.org/doi/full/ 10.1056/NEJMsa0707519.

30. Kim EJ, Kim T, Conigliaro J, Liebschutz JM, Paasche-Orlow MK, Hanchate AD. Racial and Ethnic Disparities in Diagnosis of Chronic Medical Conditions in the USA. J Gen Intern Med. 2018;33:1116-1123. https://doi.org/https://doi. org/10.1007/s11606-018-4471-1

31. Herbert A, Abel GA, Winters S, McPhail S, Elliss-Brookes L, Lyratzopoulos G. Are inequalities in cancer diagnosis through emergency presentation narrowing, widening or remaining unchanged? Longitudinal analysis of English population-based data 2006-2013. J Epidemiol Community Health 2019;73:3-10. http://dx.doi.org/https://doi.org/10.1136/jech-2017-210371

32. National Health and Nutrition Survey (MABAT). https://www.health.gov.l// English/MinistryUnits/ICDC/mabat/Pages/default.aspx. Accessed 19 Apr 2019.

33. Cookson R, Propper C, Asaria M, Raine R. Socio-Economic Inequalities in Health Care in England. Fiscal Studies. 2016;37:371-403. https://doi.org/10. 1111/j.1475-5890.2016.12109.

34. Devaux M. Income-related inequalities and inequities in health care services utilisation in 18 selected OECD countries. Eur J Health Econ. 2015;16:21. https://doi.org/https://doi.org/10.1007/s10198-013-0546-4

35. Bowling A, McKee M. Unequal access to health care in England. BMJ. 2010; 341:c3726

Ready to submit your research? Choose BMC and benefit from:

- fast, convenient online submission

- thorough peer review by experienced researchers in your field

- rapid publication on acceptance

- support for research data, including large and complex data types

- gold Open Access which fosters wider collaboration and increased citations

- maximum visibility for your research: over $100 \mathrm{M}$ website views per year

At $\mathrm{BMC}$, research is always in progress.

Learn more biomedcentral.com/submissions 